3 Woolf B. On estimating the relation between blood group and disease. Ann Hum Genet 1954-55 ; 19: 251-3.

4 Schernthaner G. New aspects in the pathogenesis and in the course of type I diabetes. Wien Klin Wochenschr 1980; 92: Supplement 114, 1-35.

5 Cudworth A G. The HLA-system, autoimmune endocrinopathy, and diabetes mellitus. Eur $J$ Clin Invest 1978; 8: 355-7.

6 Ludwig H, Schernthaner G, Mayr W R. Ia-type alloantigens and humoral autoimmune responsiveness in insulin-dependent diabetes mellitus. Metabolism 1979; 28: $797-800$.
7 Möller E, Persson B, Sterky G. HLA-phenotypes and diabetic retinopathy. Diabetologia $1978 ; 14: 155-8$.

8 Bertrams J, Dewald G, Spitznas M, Rittner Ch. HLAA, B, C, DR, Bf, $\mathbf{C}^{2}$ alleles in insulin dependent diabetes mellitus with proliferative retinopathy. Immunobiology 1981 ; in press.

Correspondence to Dr Edith Schober, Department of Paediatrics, University of Vienna, Währinger Gürtel 74-76, A-1090 Vienna IX, Austria.

Received 14 October 1980

\title{
Successful use of danazol for hereditary angio-oedema
}

\author{
C RAJAGOPAL AND J R HARPER
}

General Hospital, Northampton

SUMMARY A 10-year-old boy with severe hereditary angio-oedema was given danazol, $200 \mathrm{mg}$ each day. There was a pronounced reduction in the frequency and severity of oedema.

Danazol (17 $\alpha$-Pregna-2,4-dien-20-yno[2,3- $d$ ] isoxazol-17-ol) is an orally active pituitary gonadotrophin inhibitory agent, without oestrogenic or progestational activity. It does not appear to affect other pituitary endocrine axes and its effect on gonadotrophins is reversible. Since its introduction to the UK in 1974 it has been used in adults for endometriosis and breast disorders. ${ }^{1}$ It has been successfully used in children with precocious puberty. ${ }^{2}$

We report here the successful use of danazol for the prevention of hereditary angio-oedema.

\section{Case history}

The boy's parents came from St Helena. He was first admitted at age 3 years with painless oedema of one hand. Examination showed no other abnormality. A diagnosis of hereditary angio-oedema was confirmed on estimation of $\mathrm{Cl}$ esterase inhibitor levels, which were not detectable. His father also suffers from hereditary angio-oedema, with episodes of oedema and, occasionally, airways obstruction.

Since his original presentation he has been admitted with episodes of varying severity ranging from oedema of limbs or face to obstruction of the upper airways. Acute symptoms on these occasions were treated with fresh frozen plasma and aminocaproic acid. To try to quantitate the effects of prophylactic treatment, his symptoms were graded according to severity: grade 1, swelling of the extremities or scrotal swelling; grade 2, facial swelling, abdominal pain with or without vomiting, swollen tongue; grade 3, upper airways obstruction manifesting as stridor or dyspnoea.

During the last four years he has been admitted to hospital about 6 times a year with symptoms of grade 1 severity. In addition to this, he has had four episodes of grade 3 severity. He has been treated with aminocaproic acid during this time, but his frequent absences from school and his frequent hospital admissions have been causing concern. At age 9 years 10 months it was decided to start him on danazol $100 \mathrm{mg}$ twice daily. Before starting the drug, basal studies on puberty, growth, estimates of complement activity and testosterone levels were carried out, and were normal.

During 10 months of treatment with $100 \mathrm{mg}$ danazol twice daily, he has had only two epidoses of grade 1 symptoms and none of grades 2 or 3 . He has

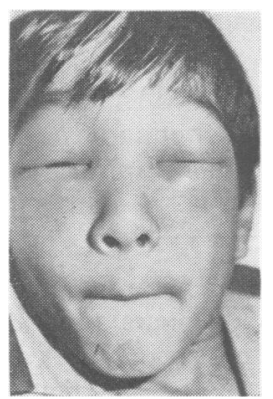

Figure Facial swelling during a bout of angio-oedema. 
not missed a single day of school since starting danazol. He has maintained a normal growth velocity and has shown no androgenic or other side effects.

\section{Discussion}

Hereditary angio-oedema is characterised by oedema of the face, airways, extremities, and gut wall. The consequences may be life threatening, particularly if it affects the larynx and trachea. ${ }^{3-4}$

It is inherited as an autosomal dominant, the essential lesion being a qualitative or quantitative deficiency of $\mathrm{Cl}$ esterase inhibitor. Under normal circumstances $\mathrm{Cl}$ inhibitor exerts a halting influence on the $\mathrm{Cl}$ component and stabilises the complement system. ${ }^{5}$ Many drugs have been tried in the treatment of this condition. Inhibitors of serine proteases-for example aminocaproic acid-were the first to be tried, followed by tranexamic acid. While these agents are useful in acute attacks, danazol has been found effective in prevention. It has been shown that danazol induces $\mathrm{Cl}$ esterase inhibitor activity and thus prevents attacks. ${ }^{6}$ We feel that the use of danazol is justified. Arguments against its use in children are mainly based on fears that it suppresses growth and gonadal function. These theoretical complications may be acceptable if there are frequent hospital admissions and the child and the parents are in constant fear of severe airways obstruction. In our patient a significant reduction in symptoms occurred on a dosage of danazol that did not cause any rise in serum testosterone level. After discussion with the boy and his parents we felt that it was correct to continue treatment, but his endocrine function is being closely monitored.

We thank the Department of Biochemistry, Northampton General Hospital for their help and Mrs M Boulby for secretarial assistance.

\section{References}

1 Potts G O. Pharmacology of danazol. J Int Med Res 1977; 5: Supplement 3, 1-14.

2 Smith C S, Harris F. Preliminary experience with danazol in children with precocious puberty. J Int Med Res 1977; 5: Supplement 3, 109-13.

3 Anonymous. Treatment of hereditary angio-oedema. Lancet 1979; i: 417.

4 Donaldson V H, Rosen F S. Hereditary angioneurotic edema : a clinical survey. Pediatrics 1966; 37: 1017-27.

5 Donaldson V H, Evan R R. A biochemical abnormality in hereditary angioneurotic edema: absence of serum inhibitor of $\mathrm{Cl}$ esterase. Am J Med $1963 ; 35$ : 37-44.

- Gelfand J A, Schein R J, Alling D W, Frank M M. Treatment of hereditary angioedema with danazol: reversal of clinical and biochemical abnormalities. N Engl J Med 1976; 295 : 1444-8.

Correspondence to Dr C Rajagopal, Department of Paediatrics, Duchess of Kent Military Hospital, Catterick, North Yorkshire.

Received 5 February 1980.

\title{
Value of the gastric aspirate shake test
}

\author{
M L SMITH, D CURNOCK, AND F FORSHAW \\ Neonatal Unit, City Hospital, Derby
}

\begin{abstract}
SUMMARY The results and predictive value of the gastric aspirate shake test are reviewed in 432 preterm babies admitted to a neonatal unit during a 3-year period. It is concluded that the degree of prematurity is a better indicator of the chance of developing idiopathic respiratory distress syndrome than the test itself.
\end{abstract}

Respiratory distress syndrome (RDS) still continues to be a common neonatal problem and is all too frequently a cause of neonatal death. The deficiency of surfactant can be predicted antenatally by measuring the lecithin-sphingomyelin ratio in amniotic fluid. ${ }^{1}$ A simple method (the shake test), also carried out on amniotic fluid, was described by Clements et al. ${ }^{2}$ This test has been used by others ${ }^{3-6}$ on gastric aspirate and the results showed that a negative result correlated well with the development of RDS. It has been suggested that the results of a shake test might help to decide whether a preterm baby should be transferred to a regional centre ${ }^{3}$ it also differentiates RDS from other causes of neonatal respiratory problems. ${ }^{\text {? }}$

\section{Patients and methods}

Since 1976 each preterm baby admitted to the 